\title{
Patient reported outcome measurements in chronic rhinosinusitis; assessing the correlation between RSOM-31 and VAS.
}

\author{
Dirk Dietz de Loos ${ }^{*}$, Lieke van der Meer, Wytske Fokkens
}

From The 10th Symposium of Experimental Rhinology and Immunology of the Nose (SERIN 2015)

Stockholm, Sweden. 19-21 February 2015

\section{Background}

Quality of Life (QoL) questionnaires are probably the most reliable outcome measurements to measure control of disease in CRS but can be relatively cumbersome. In certain situations a VAS (Visual Analogue Score) asking patients how their CRS is in general might be an easier evaluation tool.

\section{Aim}

In this study we analyse the correlation between the RSOM-31 questionnaire, a VAS overall sinus' score, and the comparable items measured as VAS.

\section{Methods}

We collected RSOM-31, 'VAS overall sinus' score and VAS per symptom and analysed correlations.

\section{Results}

705 CRS patients were included in this study (CRSwNP $\mathrm{n}=400$ ). Correlation between mean RSOM-31 and 'VAS overall sinus' score showed a moderate correlation $(\mathrm{r}=0.52)$, as did the correlation between RSOM-31 nasal domain and 'VAS overall sinus' score $(r=0.52)$. Excellent correlations between RSOM-31 and VAS were found for the comparable symptom specific questions; nasal congestion $(\mathrm{r}=0.80)$, rhinorrhea $(\mathrm{r}=0.83)$, sneezing $(\mathrm{r}=0.81)$, impaired sense of smell $(\mathrm{r}=0.82)$ and postnasal drip $(\mathrm{r}=0.86)$, all $\mathrm{p}$-values $<0.001$. None of the individual RSOM-31 items correlated well with the VAS overall sinus' score.

Academic Medical Centre, Otorhinolaryngology, Amsterdam, Netherlands

\section{Conclusion}

We found a moderate correlation between mean RSOM31 or RSOM-31 nasal domain and 'VAS overall sinus' score. The moderate correlation between these scores suggests patients, in both instruments, reflect different aspects of the burden of their disease. Further studies are needed to determine what patients include in their overall VAS score that is not captured with RSOM-31.

Published: 26 June 2015

doi:10.1186/2045-7022-5-S4-P28

Cite this article as: Dietz de Loos et al:: Patient reported outcome measurements in chronic rhinosinusitis; assessing the correlation between RSOM-31 and VAS.. Clinical and Translational Allergy 20155 (Suppl 4):P28.
Submit your next manuscript to BioMed Central and take full advantage of:

- Convenient online submission

- Thorough peer review

- No space constraints or color figure charges

- Immediate publication on acceptance

- Inclusion in PubMed, CAS, Scopus and Google Scholar

- Research which is freely available for redistribution 